\title{
Phorate e Dietholate Protegem o Arroz da Fitotoxicidade do Clomazone em Doses Elevadas ${ }^{1}$
}

\author{
Phorate and Dietholate act as Safeners for Rice Against Clomazone at High Doses
}

\author{
SANCHOTENE, D.M. ${ }^{2}$, KRUSE, N.D. ${ }^{3}$, AVILA, L.A. ${ }^{4}$, MACHADO, S.L.O. ${ }^{5}$, NICOLODI, G.A. ${ }^{6}$ e \\ DORNELLES, S.H.B. ${ }^{7}$
}

\begin{abstract}
RESUMO - O herbicida clomazone tem sua seletividade às plantas de arroz aumentada quando as sementes recebem o protetor dietholate. Sabendo que o dietholate atua sobre a atividade da enzima citocromo P-450 mono-oxigenase e que esta é responsável pela ativação do clomazone, buscam-se outros produtos que possam ser utilizados como protetores. Em vista disso, o objetivo deste experimento foi avaliar o efeito protetor do dietholate e do phorate em função de doses de clomazone. O delineamento experimental foi de blocos ao acaso com quatro repetições, em esquema fatorial. O fator A foi composto pelo tratamento de sementes com dietholate ou phorate, além de uma testemunha, que não recebeu protetor nas sementes. O fator B foi composto por oito doses de clomazone (0, 156, 312, 625, 1.250, 2.500, 5.000 e $10.000 \mathrm{~g}$ i.a. ha-1). Dezoito dias após a semeadura, foram avaliados a fitotoxicidade, o percentual de redução da estatura e a massa fresca e seca das plantas de arroz. Os dados foram submetidos à análise da variância, por meio da regressão não linear do tipo logístico. Houve diferença entre a testemunha sem protetor e os tratamentos de sementes com os protetores dietholate e phorate. Analisando as curvas de dose-resposta, verifica-se que, quando sementes do cultivar IRGA 417 foram tratadas com dietholate ou com phorate, ambos protegeram as plântulas de arroz do clomazone, ou seja, as plantas foram capazes de tolerar maiores doses de clomazone. Assim, há evidências de que os protetores de plantas dietholate e phorate atuam como inibidores da enzima citocromo P-450, impedindo que ela ative o clomazone nas plantas de arroz, proporcionando maior seletividade deste herbicida quando comparado à testemunha que não recebeu proteção.
\end{abstract}

Palavras-chave: citocromo P-450, fitotoxicidade, protetores de plantas.

ABSTRACT - Selectivity of Clomazone for rice plants increases when seeds are treated with the safener dietholate. Considering that dietholate acts on the activity of the cytochrome P450 monooxigenase, and that this enzyme also activates the herbicide clomazone, other chemicals capable of acting as safeners should also be sought. Thus, a trial was conducted aiming to evaluate the protective effect of dietholate and phorate against increasing clomazone rates. The trial was carried out in a completely randomized block design, with four replicates in a factorial scheme. Factor $A$ included seeds untreated and treated with dietholate or with phorate. Factor $B$ included eight clomazone rates $\left(0,156,312,625,1,250,2,500,5,000\right.$ and $10,000 \mathrm{~g}$ a.i. ha $\left.^{-1}\right)$. Plant injury, plant height reduction percentage, fresh mass and dry mass weight were evaluated 18 days after sowing. Data were submitted to analysis of variance by non-linear regression of the logistic type. Significant differences were observed between the control without safener and the treatments with dietholate or phorate. The dose-response curves showed that when rice seeds were treated with either dietholate or phorate, the rice plants were able to tolerate higher rates of clomazone, compared to the untreated control. Thus, this study shows that dietholate and phorate inhibit the enzyme cytochrome $P-450$, blocking the activation of clomazone in the rice plants.

Keywords: cytochrome P-450, phytotoxicity, safener.

Recebido para publicação em 27.11.2009 e na forma revisada em 12.11.2010.

2 Doutorando do Programa de Pós-Graduação em Agronomia, Universidade Federal de Santa Maria -UFSM, <dmartisan@mail.ufsm.br>; ${ }^{3}$ Professor Adjunto, Dep.de Defesa Fitossanitária, UFSM; ${ }^{4}$ Professor Adjunto, Dep. de Fitotecnia, Universidade Federal de Pelotas - UFPel; ${ }^{5}$ Professor Titular, Dep. de Defesa Fitossanitária, UFSM; ${ }^{6}$ Eng $^{\mathrm{a}}$-Agr ${ }^{\mathrm{a}}$., Mestre em Agronomia; ${ }^{7}$ Professor Adjunto, Dep. de Biologia, UFSM. 


\section{INTRODUÇÃO}

Protetores de plantas, ou safeners, são produtos químicos usados com a finalidade de promover a seletividade de herbicidas, por meio da proteção da cultura à fitotoxicidade do herbicida, sem reduzir a eficiência no controle das plantas daninhas. Apesar de os efeitos de alguns protetores encontrados no mercado de agroquímicos já terem sido comprovados, os mecanismos fisiológicos e bioquímicos exatos envolvidos na seletividade ainda não estão totalmente esclarecidos (Ezra et al., 1983).

Está registrado para a cultura do arroz irrigado o protetor dietholate, que permite ao arroz tolerar doses de clomazone acima da recomendação técnica para a cultura não tratada. O uso do dietholate no tratamento de sementes confere às plantas delas oriundas tolerância a maiores doses de clomazone (Karam et al., 2003). Estudos na cultura do algodão mostram que diversos inseticidas do grupo químico dos organofosforados, como malation, phorate, zineb, entre outros, são capazes de inibir a enzima citocromo P-450 nas plantas tratadas, tornando-as mais tolerantes a doses de clomazone (Ferhatoglu et al., 2005). A enzima citocromo P-450 mono-oxigenase nas plantas possui a função de detoxificação de certos compostos. Essa enzima é também a responsável pela oxidação das moléculas do clomazone, tornando-as mais tóxicas às plantas que possuem maior capacidade de oxidação (Yun et al., 2005).

Buscando ampliar as evidências de que a ação protetora do dietholate consiste de fato na inibiçao da enzima citocromo P-450 monooxigenase, assumiu-se que outros compostos presumidamente inibidores dessa enzima também poderiam aumentar a seletividade do clomazone ao arroz. Em vista do exposto, foi desenvolvido um experimento com o objetivo de verificar se o phorate tem atividade protetora do arroz irrigado a doses elevadas de clomazone.

\section{MATERIAL E MÉTODOS}

O experimento foi conduzido em casa de vegetação da Universidade Federal de Santa Maria, durante o ano de 2008. O delineamento experimental foi de blocos ao acaso em esquema fatorial $3 \times 8$, com quatro repetições, sendo os tratamentos do fator A representados pelo tratamento de sementes, em três níveis: semeadura de sementes sem tratamento, sementes tratadas com dietholate e tratamento com phorate. $O$ fator $B$ constou da aplicação de doses crescentes de clomazone $(0,156,312$, $625,1.250,2.500,5.000$ e 10.000 g i.a. ha-1). O cultivar de arroz utilizado foi o IRGA 417.

O experimento foi conduzido em vasos de polietileno de 1,4 L de capacidade, revestidos internamente com plásticos e preenchidos com 1.200 gramas de solo, o qual foi classificado como Planossolo Hidromórfico Eutrófico arênico, pertencente à unidade de mapeamento Vacacaí, com as seguintes características: $\mathrm{pH}$ água( $(1: 1)=4,7 ; \mathrm{P}=6,0 \mathrm{mg} \mathrm{dm}^{-3}$; $\mathrm{K}=112 \mathrm{mg} \mathrm{dm}^{-3} ;$ argila $=16 \% ; \mathrm{MO}=1,6 \%$; $\mathrm{Ca}=2,2 \mathrm{cmol}_{\mathrm{c}} \mathrm{dm}^{-3} ; \mathrm{Mg}=2,0 \mathrm{cmol}_{\mathrm{c}} \mathrm{dm}^{-3}$; $\mathrm{Al}=1,7 \mathrm{cmol}_{\mathrm{c}} \mathrm{dm}^{-3} ;$ e índice SMP: 6,6. Após o preenchimento dos vasos, mediu-se a umidade gravimétrica, a fim de determinar a massa de solo seco adicionada nos vasos.

A quantidade de água necessária para cada unidade experimental foi determinada por meio da metodologia de coluna úmida (Forsythe, 1975). Esse manejo foi realizado a cada dois dias, através da medição da massa de cada vaso e adicionando-se água até atingir a massa total. Antes da semeadura, as sementes foram tratadas com dietholate (0,0-diethyl 0-phenyl phosphorothioate) na dose de $1.000 \mathrm{~g}$ de produto comercial por $100 \mathrm{~kg}$ de semente, ou com o inseticida phorate, pertencente ao grupo químico dos organofosforados, na dose de $2 \mathrm{~g}$ de ingrediente ativo do organofosforado phorate para $10 \mathrm{~g}$ de semente do cultivar IRGA 417 (20 kg $100 \mathrm{~kg}^{-1}$ semente).

A semeadura nos vasos ocorreu em $15 \mathrm{de}$ outubro de 2008, e a aplicação dos tratamentos herbicidas em pré-emergência do arroz, no dia 16 de outubro de 2008. Foram realizadas avaliações visuais de fitotoxicidade, seguindo a escala porcentual, em que $0 \%$ representou ausência de dano e $100 \%$, morte das plantas (Frans \& Crowley, 1986). Ao final do décimo oitavo dia foram realizadas a contagem do número de plantas por vaso, a coleta das plantas para determinação de sua massa fresca (MF), a medição da estatura de plantas (EST) e, após secagem em estufa a $60^{\circ} \mathrm{C}$ até massa constante, da massa seca (MS) de plantas. Os 
dados foram submetidos à análise de variância (ANOVA), para verificação das interações entre os fatores e entre os niveis do fator A. Para as interações significativas, os dados foram ajustados ao modelo de regressão não linear do tipo log-logístico, usando-se o modelo proposto por Seefeldt et al. (1995).

$$
Y=C+\left(\frac{D-C}{1+e^{\left[b\left(\log (x)-\log \left(X_{50}\right)\right)\right]}}\right)
$$

em que $D$ representa o limite superior; $C$ representa o limite inferior; o parâmetro $b$ descreve a inclinação da curva em torno do $\mathrm{I}_{50 \text {; }}$ e os valores de $\mathrm{I}_{50}$ correspondem à dose que causa resposta de $50 \%$ da assintota de máxima da variável resposta.

\section{RESULTADOS E DISCUSSÃO}

Analisando os resultados obtidos por meio das curvas apresentadas na Figura 1A e B, verifica-se que as curvas de dose-resposta contendo protetores de sementes dietholate e phorate ficaram acima da curva sem protetor. Os valores estimados de $\mathrm{I}_{50}$ demonstram que, para os dois protetores utilizados (dietholate e phorate), as doses necessárias para causar $50 \%$ de redução da variável dependente foram maiores que aquelas do tratamento sem protetor (Tabela 1), independentemente da variável avaliada (fitotoxicidade, massa fresca de plantas, massa seca e estatura de plantas de arroz). Quando comparados os valores de $I_{50}$ do tratamento com dietholate versus o tratamento com phorate, não é evidenciada

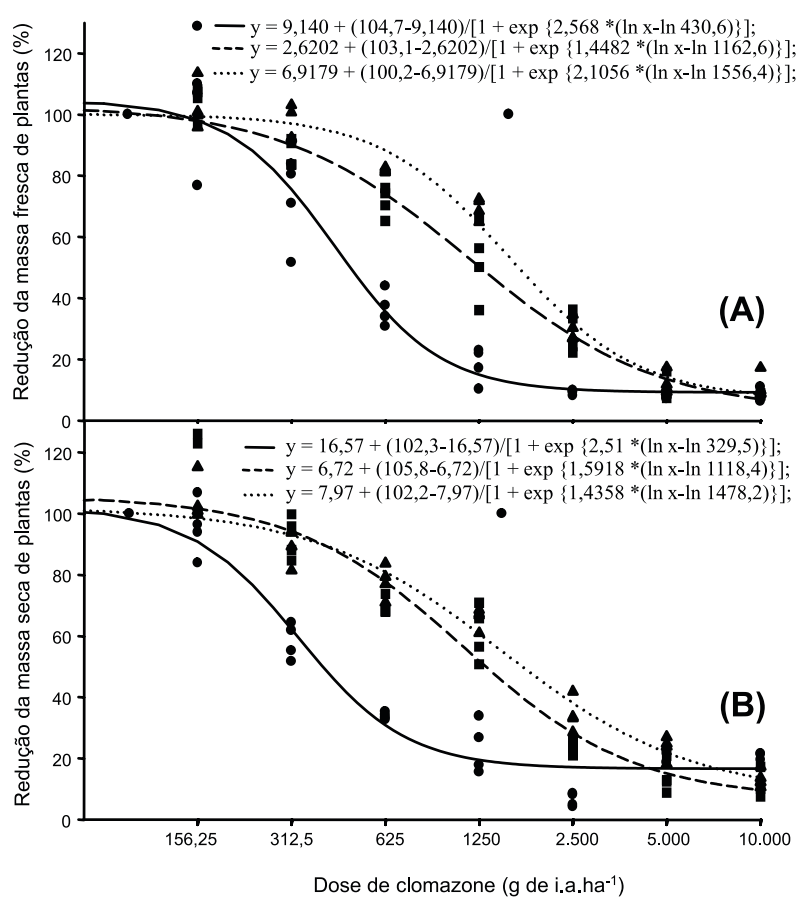

Figura 1 - Curvas de dose-resposta do arroz irrigado (Cultivar IRGA 417) ao herbicida clomazone, sem a adição de protetor (-), com o protetor dietholate (---) e com o protetor phorate (...), ambos aplicados como tratamento de sementes. Redução da massa fresca (A) e de massa seca de plantas (B). Santa Maria-RS, 2009

diferença significativa entre os tratamentos, pois os intervalos de confiança se sobrepõem.

Os valores do fator de proteção (FP) calculado para cada protetor demonstram quanto se pode aumentar a dose do herbicida para obter o mesmo nível de $\mathrm{I}_{50}$ nas variáveis (FT, EST, $\mathrm{MF}$ e MS), em relação às plantas não tratadas. Salienta-se que para a variável estatura

Tabela 1 - Doses de clomazone em (g i.a. ha ${ }^{-1}$ ) que causam 50\% de fitotoxicidade $\left(\mathrm{FT}_{50}\right), 50 \%$ de redução da estatura de planta $\left(\mathrm{EST}_{50}\right), 50 \%$ de redução de massa fresca de plantas $\left(\mathrm{MF}_{50}\right)$ e $50 \%$ de redução de massa seca de plantas $\left(\mathrm{MS}_{50}\right)$ e seus respectivos intervalos de confiança em $95 \%$ de probabilidade, em função do tratamento de semente com protetores. Santa Maria-RS, 2009

\begin{tabular}{|l|c|c|c|c|}
\hline & $\mathrm{FT}_{50}$ & $\mathrm{EST}_{50}$ & $\mathrm{MF}_{50}$ & $\mathrm{MS}_{50}$ \\
\hline Sem protetor & $432,8 \pm 60,3$ & $315,3 \pm 30,1$ & $353,7 \pm 76,9$ & $329,5 \pm 49,4$ \\
\hline Dietholate & $794,0 \pm 122,8$ & $1.120,3 \pm 300,4$ & $1.162,6 \pm 249,5$ & $1.118,4 \pm 302,2$ \\
\hline Phorate & $953,7 \pm 227,0$ & $1.664,2 \pm 248,8$ & $1.556,4 \pm 197,7$ & $1.478,2 \pm 333,4$ \\
\hline & \multicolumn{5}{|c|}{ Fator de proteção } \\
\hline Dietholate & 1,83 & 3,55 & 3,28 & 3,39 \\
\hline Phorate & 2,20 & 5,24 & 4,40 & 4,48 \\
\hline
\end{tabular}

FP - fator de proteção do dietholate calculado a partir da razão dos $\mathrm{I}_{50}$ dos tratamentos com protetores pelo tratamento sem protetor, em relação a $\mathrm{FT}_{50}, \mathrm{EST}_{50}, \mathrm{MF}_{50}$ e $\mathrm{MS}_{50}$ em plantas de arroz. 
de plantas o tratamento com protetor de plantas phorate proporcionou maior proteção às plantas, tolerando até cinco vezes a dose de clomazone (g de i.a. ha ${ }^{-1}$ ), quando comparado ao tratamento sem protetor. Apesar de não haver diferença estatística significativa entre os protetores dietholate e phorate, verifica-se que phorate apresentou proteção que possibilitou incrementar quatro vezes a dose do herbicida para um mesmo $\mathrm{MF}_{50}$, enquanto para dietholate a dose foi aproximadamente três vezes maior que aquela que causou $50 \%$ de redução na massa fresca.

Os resultados deste experimento corroboram os obtidos por Concenço et al. (2006), que observaram que clomazone em solos com característica semelhante acarretou diminuição significativa na densidade populacional das plantas, aumentando o grau de fitotoxicidade. $\mathrm{O}$ efeito protetor do dietholate e do phorate a doses superiores às suportadas pelo arroz irrigado sem tratamento pode ser explicado em função da inibição da produção de metabólitos ativos de clomazone nessas plantas, o que impede a ação fitotóxica desse herbicida (Norman et al., 1990). Nesse sentido, segundo Ferhatoglu et al. (2005), a produção desses metabólitos está diretamente relacionada com as reações de oxidação e redução que ocorrem nas plantas, dependentes da concentração de NADPH nas células (Deng et al., 2002). A oxidação é catalisada pela enzima citocromo P-450 mono-oxigenase, que tem sua atividade inibida pelo dietholate e por alguns inseticidas do grupo químico dos organofosforados, entre eles o phorate. Assim, inibindo a atividade da enzima citocromo P-450, o dietholate e o phorate interferem na catalisação da NADPH e na produção de metabólitos ativos do clomazone, principalmente o 5-OH-clomazone e o 5-ceto clomazone (Ferhatoglu et al., 2005), envolvidos na rota não mevalonato responsável pela sintese dos carotenoides - rota descrita por Dubey et al. (2003). Portanto, com a evidência de que não somente o dietholate, mas também o phorate, outro provável inibidor da enzima citocromo P-450, também confere proteção às plantas tratadas contra a ação do herbicida clomazone, sustenta-se que o mecanismo pelo qual esses compostos exercem essa proteção encontra-se no bloqueio da ativação do herbicida, por meio da sua não oxidação.

\section{LITERATURA CITADA}

CONCENÇO, G. et al. Efeito de herbicidas aplicados em préemergência e momentos de início da irrigação no crescimento de plantas de arroz. Planta Daninha, v. 24, n. 2, p. 295-301, 2006.

DENG, F.; HATZIOS, K. K. Characterization of cytochrome $\mathrm{P} 450$ - mediated bensulfuron-methyl O-demethylation in rice. Pestic. Biochem. Physiol., v. 74, n. 2, p. 102-104, 2002.

DUBEY, V. S. et al. An overview on the nonmevalonate pathway for terpenoid biosynthesis in plants. J. Biosci., v. 28, n. 5 , p. $637-646,2003$

EZRA, G. et al. Effects of the herbicide EPTC and the protectant DDCA on incorporation and distribution of [2-14]-acetate into major fractions of maize cell suspension cultures. Pestic. Biochem. Physiol., v. 19, n. 3, p. 225-234, 1983.

FERHATOGLU, Y. et al. The basic for safening of clomazone by phorate insecticide in cotton and inhibitors of cytochrome P450s. Pestic. Biochem. Physiol., v. 81, n. 1, p. 59-70, 2005.

FORSYTHE, W. Física de suelos: manual de laboratório. San José, Costa Rica, Instituto Interamericano de Ciência Agrícola, 1975. 212 p.

FRANS, R.; CROWLEY, H. Experimental design and techniques for measuring and analyzing plant responses to weed control practices. In: SOUTHERN WEED SCIENSE SOCIETY. Research methods in weed science. 3.ed. 1986. p. $29-45$

KARAM, D. et al. Seletividade da cultura do milho ao herbicida clomazone por meio do uso de dietholate. R. Bras. Milho Sorgo, v. 2, n. 1, p. 72-79, 2003.

NORMAN, M.A. et al. Site of clomazone action in tolerantsoybean and susceptible-cotton photomixotrophic cell suspension cultures. Plant Physiol., v. 94, n. 2, p. 704-709, 1990.

SEEFELDT, S. S. et al. Log-logistic analysis of herbicide dose-response relationships. Weed Technol., v. 9, n. 2, p. 218-227, 1995.

YUN, M. S. et al. Cytochrome P-450 monooxygenase activity in herbicide-resistant and - susceptible late watergrass (Echinochloa phyllopogon). Pestic. Biochem. Physiol., v. 83, n. 2-3, p. 107-114, 2005. 